\title{
The Nursing Dean's World: Professional and Personal Lives
}

\author{
Lesley Wilkes ${ }^{1, *}$, Debra Jackson ${ }^{2}$, John Daly $^{3}$, Wendy Cross ${ }^{4}$ \\ ${ }^{1}$ Centre for Nursing Research and Practice Development- University of Western Sydney, Nepean Blue Mountains Local Health District, \\ Nepean Hospital, Australia \\ ${ }^{2}$ Faculty of Health and Life Sciences Oxford Brookes University, UK \\ ${ }^{3}$ Faculty of Health, University of Technology Sydney, Australia \\ ${ }^{4}$ School of Nursing \& Midwifery Monash University, Faculty of Medicine, Nursing and Health Sciences, Australia
}

Copyright $(\subset 2015$ by authors, all rights reserved. Authors agree that this article remains permanently open access under the terms of the Creative Commons Attribution License 4.0 International License

\begin{abstract}
Purpose- The purpose of this paper is to report the results of a study which aimed to describe the ways a group of deans of nursing integrated their professional and personal lives in their worlds. Methods- Oral histories were collected from a group of 30 deans from three countries Canada, England and Australia. The data from the interviews were content analysed for themes related to the deans' personal and professional life experiences. Through contrast and comparison of these themes, the researchers wrote a description of how the deans integrated their personal and professional lives. Results- The major themes that emerged from the analysis were: work demands, dual career partnerships, children come first, obtaining educational qualifications, other professional activities, and out of work activities. Conclusion- The world of the dean of nursing working in a complex university structure is complex and often impacts on the rest of their lives. However, it is important to see that their personal lives and how they live them can revitalise and give them emotional strength for their professional life. The study has implications for deans who need to reflect on how they integrate the two lives in their worlds by identifying stress and taking advantage of developmental opportunities.
\end{abstract}

Keywords Academic Dean, Work Life Balance, Qualitative Research

\section{Introduction}

There are challenges in keeping up with work and life, particularly in a world where organisations maintain the assumed norm that workers work in a breadwinner-homemaker model [1]. Family profiles have changed with more dual-career couples and single parents in the workforce. This juggling is difficult for people in many professions. However, as in many female dominated disciplines, such as education and librarianship deans of nursing must juggle in a unique, complex way because they work in environments where they need to lead their faculties with vision, passion, patience, and courage, sharing and being supportive and facilitative at the same time [2]. They also need to have high communication skills, develop faculty, be role models, be good managers of diverse programs which need external accreditation, and promote nursing internally and externally to their institution [2]. This paper reports how the professional and personal lives of a group of deans exist in their worlds.

Background

The concept of work/life is usually coupled with balance in the literature [1], with implication that a dichotomy exists between work and family or work and personal life. As suggested by Haddock et al. [3], work/life encompasses emotional, spiritual, physical and developmental components using experiences and beliefs to live in the present and take action. It is implied that to achieve work/life balance there should be an equal distribution of work and life [4]. However, it is often stated in the literature that people are "ideal workers": either full time blue collar workers in the working class or high level executives and professionals in the middle class context [5]. These "ideal workers" must subordinate all other elements of their life to the requirements of the job [1]. This often causes people to struggle. We also found when investigating deans of nursing there were significant emotional demands on them where work/life balance could be an issue [6]. Work is an important, meaningful part of life. For most people, work and personal lives need to exist side by side and be equally valued rather than be in conflict with each other Bailyn et al. [1]. Can people work in society today with the demands of long hours at work, caregiving at home, and single and dual career partnerships couples being more the norm [5]. As suggested by Bailey $\mathrm{Jr}$ [7] in her investigation of community 
occupational deans integration or weaving of work with their personal lives is more expressive of the situation than trying to maintain work/life balance. In the context of this paper, the terms professional (work role as a dean of nursing) and personal (not related to this work role) lives are used.

Research on the integration of personal and professional lives of deans is scant in the literature. However, when interviewing deans in community colleges in the United States of America, Bailey Jr [7] found that although the deans espoused integration of work and life they worked " with a misalignment of their heavy workloads to personal responsibilities." Similarly, in their survey study of deans in community colleges, $41 \%$ women found that establishing a professional and personal balance was impacted by the demands of work time consuming the deans Montez et al. [8]. In a study by Friedman et al. [9], the deans stated that they needed to enrich their personal life to have a productive work life. Another study by this group on deans of education found they were consumed by work and found it hard to find balance Wolverton et al. [10].

\section{AIM}

As there is little written on the integration of the personal and professional lives of deans and in particular deans of nursing, the aim of this paper is to describe ways a group of deans of nursing integrated their professional and personal lives in their worlds. The data for this paper come from a larger qualitative international study of deans of nursing, which investigated their career pathways, the leadership styles they considered essential for the position of dean, and the impact of the role on their personal and professional lives. In the context of the study, deans of nursing were seen as senior members of the academic staff of a university, heading a nursing faculty/school and responsible for faculty personnel and nursing programs.

\section{Methods}

The study, which was conducted in three countries Canada, England and Australia, used personal oral histories to collect data. This approach allows the collection of personal biographies to explicate the culture and behaviours of a specific group; in this case, deans of nursing [11, 12].

\section{Participants and Recruitment}

Participants were nurses who had held or were holding the position of dean for at least one year at any time from the 1980s to March 2012. The participants were recruited through the team's contacts and public web sites of universities in Canada, England and Australia. The deans were invited by email so that there would be no coercion to be involved, who were also asked to contact the team for an information sheet and consent forms if they wished to be part of the project.

\section{Data Collection}

Data were collected between July 2011 and March 2012 using a semi-structured interview schedule with a set of questions including the deans' stories of becoming nurses, their career and educational pathways to the dean position, key characteristics of leadership for deans of nursing, challenges and opportunities as a dean, their personal and professional lives, and advice to others wanting to be dean. All interviews were digitally recorded. Some were conducted at a place convenient to the participants and others were conducted over telephone.

\section{Data Analysis}

The texts from the interview were transcribed and content analysed for themes related to various concepts of the interview schedule. The coded data were entered into NVivo [13]. For this paper, themes and relevant exemplars related to integrating personal and professional lives were extracted from the data. Through contrast and comparison of these themes and exemplars, we wrote a description of how the deans integrated their personal and professional lives. To maintain rigor, the themes and exemplars were checked by all members of the team. An audit trail of interview texts, how the themes were identified and finally decided, collated and organised was kept and checked as well to reach agreement before a final decision on the description was made.

\section{Ethical Considerations}

The project was approved by Human Research Ethics committees of the three universities where the team members work. All quotes from the transcribed text of the interviews were de-identified and Dean 1-30 for individual deans used for anonymity purposes.

\section{Results}

\section{Participants}

Thirty deans form the sample for this study; twenty came from Australia, three from Canada and seven from England. Most $(22,70 \%)$ were women. The age of the deans ranged from 45 to 75 years (Mean $=57$, SD 7) and years in a dean position were from 1 to 22 years (Mean $=8.4$, SD 5.98). All but three of the deans had $\mathrm{PhD}$, with the three others having clinical Master of Nursing degrees. Of the other deans who had masters' degrees, these included two in management in nursing or related health discipline and six in education.

\section{Professional and Personal Lives}

As indicated in the paper by Wilkes et al. [2], the careers of these deans of nursing triggered emotional demands. Maintaining a personal life while integrating the demands of their career and leading their faculty in an executive management position at a university is elaborated in the following themes extracted from their conversations. The major themes to be described are: work demands, dual career 
partnerships and children come first, obtaining educational qualifications, other professional activities, and out of work pleasure activities.

For this group of deans, long hours at work and work demands made it difficult for them to integrate personal and professional lives. For me I haven't balanced my life well (Dean 29); we are doing the best we can (Dean 3); we don't always think about it - I have good time and bad time often work is overwhelming and life takes second spot ( Dean 5). One male dean reflected: when I was younger I didn't get home until late; now I got home at 10pm and went to bedno work life balance there. As I am getting older I am more sensible, I hope (Dean 6). One dean had a ... [chronically ill child]... so she felt she had high workload at work and home: I am in a position that a lot of other people wouldn't be in because I am a sole and primary carer of a child with a severe chronic illness so I sort of go home from work and just move into another shift (Dean 28).

Work demands included the never ending flow of emails. Dean 22 and others had set up a system where they did emails for a set time each day. Some, like Dean 22, suggested setting boundaries, demarcating time for family and time for work, not working on the weekend or taking work home (Dean 22). Dean 18 worked away from home during the week and balanced work and home this way: I am probably not as good as I should be. I am living up here and my husband is in the south and I'm doing a fair bit of commuting. I tend to work longer hours during the week and therefore tend to have my weekends pretty free. Another dean had two residencies, one near the workplace, and the other near children where they could relax and play at the weekend: I do long hours at work but we have bought a caravan near our son so it's almost my escape and I often now say I have two lives. When I go to the caravan I am going to my other life which is my family and when I come back here I am going into work life (Dean 8). However, others found it difficult to be flexible particularly with time at work: I don't do it well because I'm work oriented, not by choice. I do a 12 hour day and I'm finding I cannot sustain that in the ways I could when I was younger so I use my weekends really as rest time and I'm doing anything social (Dean 24). Others like Dean 15 felt the same. Finally, you work evening you work weekends because it's part of the job (Dean 8).

Only one dean mentioned that working and travelling from home to work has affected her health: I was here 12 months and hospitalised. I was doing 14 hours a day. I travelled one hour each way to work and home. I ended up getting sick because of the long hours on the road... now I am on medication for life (Dean 24).

Most deans appeared resilient in their integration of professional and personal lives. This is encapsulated by one dean's statement: I think by my nature I'm an optimist. I don't define my life in terms of problems. I also have a stable family environment so that was a good retreat and I do actually enjoy what I do (Dean 10).

A number of the deans were in dual career partnerships and this impacted on the way they managed their lives. One dean felt she handled this well and found it balancing: It's critical you don't come consumed with your dean role that you cannot see the wood for the trees. I go to military events with my husband and talk to people who have just as busy lives ... it helps you look at things differently (Dean 2). Others felt there was often a sway in the male partner's side: My then husband did not feel he had any role in family life. When our daughter was young I had to work part time, pick her up from school, I did my PhD part time, worked a little and was her mother. But I did achieve what I set out to do (Dean 26). Similar to case other deans sacrificed their marriages during the building of their career: the last couple of years have been messy ... I left my husband (Dean 21). Another dean also suggested that work contributed to her marriage breakdown: I didn't get support at work, it was very stressful and it contributed to my marriage breakdown (Dean 19). For others, there was just no time for relationships: $I$ cannot maintain a relationship, I don't have a husband any more, I am far away from my children, I don't see my grandchildren as often as I would like ... my personal relationships have been sacrificed... I have lost relationships because of my success in my life (Dean 13).

For most of the deans, the support of their partner and family was paramount for them to survive the challenges of their career: I don't think my family life has affected my career. It's been very supportive enabling really and the partnership has been a good one to enable me to progress the way I have (Dean 12). However, it could be difficult: In the early days, getting qualifications meant a lot of midnight reading and at the same time dealing with babies and toddlers. My wife had a career and getting both balanced was difficult. Later I travelled a lot and there both been a cost at home and in my career (Dean11). The inflexibility of having a family could impact on their career development and mobility, not enabling them to make opportunities or take up new positions as deans. Dean 22 stated: My mobility and therefore my promotional opportunities were limited by my family. Often in universities it's easier to leave a university and move around to get a promotion then try to stay in one institution and go through the promotional process.

Although most of the deans were women (12, 70\%), both the men and women with children felt that their children come first: socialising and work secondary to the children; for both of us if there was any time then it should be for the children not for us to socialise (Dean 17). However, some had sacrificed attending school and other events when they were building their career and establishing themselves as a dean: you don't get to all the school, kids' events at school (Dean 27). Another dean reflected:

Early on I needed to have a job that I could be home with the children at weekends so I went into education. But I look back and wonder if I missed too much in their lives when they were young. Now I am spending quality time with my children and grandchildren (Dean 4).

When in the dean position work demands often took over: my daughter, she is kindly soul would say I'm the best 
mother ever but probably 15 years ago my children would have said I was the crappiest mother on earth, because I always put work first (Dean 15). For others, they felt their career was impeded early in their career with young children, as one female dean reflected: When they left home I went overseas. So it's worked out well. But yes, when they were little I would say it did hinder opportunity a little. Because, it's my choice and that's fine with me, that's fine that's fine (Dean 13).

One dean argued that early in her career when she was educating herself and looking after young children the flexible hours of academia helped: academia gives you the flexibility that other occupations don't and so I think when my children were young in those years so that I could set my work hours and occasionally work from home (Dean 21). However, this freedom was lost when she took on leadership roles in the university.

Obtaining educational qualifications had mounted a toll on the deans with $23(76.6 \%)$ studying for their $\mathrm{PhD}$ part time and having a plethora of other qualifications collected during the building of their career. This often impacted on the prioritising of their children, as Dean 4 stated: my son always said I was always doing homework during the time I was studying for degrees. Most of the Deans (15, 50\%) had obtained their $\mathrm{PhD}$ while a lecturer at university, ten (33.3\%) while in a leadership position in a faulty/school of nursing and only two while a dean. One dean was enrolled in a $\mathrm{PhD}$ at the time of interview.

Some of the deans used other professional activities away from management to sustain their morale and make themselves feel their own persona. For example, one dean (Dean 15) maintained a clinical practice in psychology and others used time pursuing scholarly activities such as writing articles or books to keep themselves "sane": I've managed to maintain a clinical role even as head of school right throughout my career...It's only half a day a week; you know in a funny sort of way it actually allows one to be recharge your batteries (Dean 29). Others used trips overseas and conferences to meet other nursing academics as a break, as Dean 12 stated: I always make time at least one or two weeks a year to do something for me - conference, WHO and ICN work. It allowed them to network and revitalise themselves. Doing research for some was a way of maintaining equilibrium; others published books or journal articles. One dean had organised sabbatical leave after much negotiation with higher management:

The most recent thing I did to sustain myself was to take 12 months sabbatical. For six months I was a visiting professor at a UK university. Reconnecting with this university was extraordinarily beneficial. It helped me push publications and organise research projects that would sustain me during the term as head of school (Dean 29).

Personal space was important to most of the deans. One dean reflected: I have had people who say we're having a breakfast meeting and I'll say I cannot go because I need that hour in the morning. I need to go for a swim, I need to walk on the beach and I just think without you personally getting yourself fit and making time for yourself you're no good to anyone (Dean 23).

Out of work pleasure activities were very important to the Deans. One Dean felt in order to maintain this she needed structure and had completed a horticulture qualification while a dean. She said: I did it ... [qualification] ...because I don't do anything except work, if I start a hobby that is just a hobby I won't do it... I need to go to classes and do assessments... and I have met other people I would not have met (Dean 1). Gardening was also a choice of other deans, but in a less organised fashion (Deans 10, 12). Others needed order in their personal activities and they did this by maintaining membership in group activities: I could become consumed with work so I need balance with work ... I am part of a group Corporate Athlete so I walk every day (Dean 13). Dean 7 was also involved in organised club sport crown green bowls. For many, exercise was the activity of choice, which could include swimming, walking, kayaking or going to the gym. For one dean, it was exercise but included painting and taking photos. However, work would often invade home life: there are often social events for work in home time. On Sunday I am usually preparing for executive meeting on Monday with vice chancellor (Dean 7). Others chose to go to the theatre to keep sustained and organised in their personal life: I like theatre subscriptions and dates ... so at least some other part of my life is going on (Dean 25). She went on to emphasise the need to maintain adequate rest. For most, but not all, of the deans, some form of outside personal distraction was essential to survival.

\section{Discussion}

Similar to reported studies in the introduction, it was hard for this group of deans of nursing to not be the "ideal worker". They tended to have work as the centre of their world with their personal lives floating around, which were either interwoven into the web of their work life or sitting side by side. Children appeared to help maintain a focus on home but often they were left to fend for themselves and there was obvious pressure to get to children's events at school or elsewhere. As Morehead [14] suggests, management of absence from home is paramount for women to support a balance to work. She found that with nurses where hours are regulated by others it was difficult for them to leave work, for example, if a child was sick. However, academics who had more flexible hours could reorganise their day for such emergencies [15]. Morehead [14] also argues having restriction in workload flexibility helped women in particular to organise their work and home lives. However, deans do not have flexibility when they are in senior leadership roles in universities. As many of the deans were women, the pressure of work and home often brought about divorce and the inability to maintain relationships. As suggested by Heikkinen et al. [16], spousal support can be dynamic and changing and spousal non-support in general is often experienced by women managers. Woodward [17] 
argues for women to be supported at home, they may need to give up the gatekeeper role on domestic issues - there must be sharing.

As detailed in our paper on the career and educational pathways of this group of deans Wilkes et al. [18], they had accumulated a plethora of qualifications during their career building, and as indicated in the findings in this paper, this striving for essential qualifications did impact on their prioritising of their children and home life. Doing study was often easier when they were in non-management positions at university as hours could be made more flexible [17].

Doing recreation and leisure activities has been shown to be a positive way to counteract the emotional and physical demands of work Woodward [17]. For this group of deans, this was seen in the main as important, but for some of them this needed to be a timetabled group activity such as a sport club or a structured program on gardening. Unlike other studies Nelson et al. [19] where exercise was seen as more important to the male executive, most of the deans whether male or female used exercise of some sort to revive themselves. For others, they managed to organise themselves and do activities they liked. While it has been shown that women in high stress work positions tend to use two mechanisms to remain healthy such as maintaining healthy eating patterns and maintaining positive attitudes Lindquist et al. [20], the Deans in this study did talk of positive optimism but none spoke of maintaining healthy eating habits. It's interesting that some of the deans used other professional work such as research, writing and going to conferences outside their dean management role to equalise the work pressure of making management decisions. Many of the findings from this study mirror the small study of Woodward [17] on women in management positions at UK universities managing work/life balance. These include setting boundaries, and making a shift towards work when the demands were there. It was clear that women without children were more inclined to change boundaries then those with children, especially with preschool children. This is also noted by Ahmad et al. [21].

Being a dean of nursing in complex university structure is hard with work demands often determining the rest of their lives. However, it is important to reflect on how these demands can be equalised by personal lives which can provide avenues for the deans to revitalise themselves. While not forgetting that integrating professional and personal life is not easy, if it is done well, it can provide deans of nursing with more emotional strength in a busy world.

This study was limited due to the fact that the stories were self-reports of their worlds and no cross checking with other people in their lives was made. To gain another view to their worlds, outsiders who don't aspire to become Deans could be interviewed.

\section{Conclusions}

The findings in this study about integrating personal and professional lives have implications for current and aspiring deans of nursing as they do for any nurse in a leadership role in both the health and academic arenas. Personally, people in these executive roles need to reflect on what they do and how they do it to try to integrate their professional and personal lives. They need to identify sources of stress, take advantage of developmental opportunities, recognise that personal and professional lives are hard to maintain in equilibrium but they must work towards not just being an ideal worker.

For organisations, both in health and academia, providing ways to enable better support for nurses in executive roles such as deans or directors of nursing is essential. Further research into the integration of personal and professional lives for not only executives but nurses in management positions at the ward level is required. They need to provide opportunities for deans to debrief and identify ways deans can be supported to take opportunities to increase and promote their emotional resilience.

\section{Acknowledgements}

We are grateful to Anna McManus, Dr. Irene Chen and Harrison $\mathrm{Ng}$ Chok for their support in publishing this document.

\section{REFERENCES}

[1] Bailyn, L., R. Drago, and T.A. Kochan. Integrating Work and Family Life a holistic approach Sloan School of Management, Editor 2001, MIT, Sloan School of Management. Boston. p. 60 .

[2] Wilkes, L., W. Cross, D. Jackson, and J. Daly. A repertoire of leadership attributes: an international study of deans of nursing. Journal of Nursing Management, 2013: p. n/a-n/a.

[3] Haddock, S., T. Zimmerman, S. Ziemba, and L. Curent. Ten adaptive strategies for family and work balance: advice from successful families. Journal of Marital and Family Therapy, 2001. 27(4): p. 445-458.

[4] Ward, K. Creating life: Productivity and passion in careers in higher education. in EAERA Division J Graduate Student and New Faculty Pre-Conference Seminar. 2003. Chicago, IL.

[5] Joan, W. Unbending gender: Why family and work conflict and what to do about it, 2000, New York: Oxford University Press.

[6] Jackson, D., J. Daly, W. Cross, and L. Wilkes. The emotional demands of nursing leadership: challenges and strategies for career, in Royal College of Nursing 2013, RCN: Belfast.

[7] Bailey Jr, A.D. Perspectives on the auditing profession part II: The academic profession. Current Issues in Auditing, 2008. 2(1): p. C37-C45.

[8] Montez, J., M. Wolverton, and Gmelch WH. The roles and challenges of deans. The Review of Higher Education, 2003. 26(2): p. 241-266. 
[9] Friedman, S.D., P. Christensen, and J. DeGroot. Work and Life: The End of The Zero-Sum Game. Harvard Business Review, 1998: p. 119-129.

[10] Wolverton, M., M.L. Wolverton, and W.H. Gmelch. The Impact of Role Conflict and Ambiguity on Academic Deans. The Journal of Higher Education 1999. 70(1): p. 80-106.

[11] Thompson, G. Unfulfilled prophecy: The evolution of corporate colleges. Journal of Higher Education, 2000. 71(3): p. 322-341.

[12] Kirby, S. A historical perspective on the contrasting experiences of nurses as research subjects and research activists. International journal of nursing practice, 2004. 10(6): p. 272-279.

[13] QSR International Pty Ltd, NVivo qualitative data analysis software, 2012.

[14] Morehead, A. Beyond preference and choice: how mothers allocate time to work and family. in Families Matter AIFS Conference. 2005.

[15] Probert, B. 'I Just Couldn't Fit It In': Gender and Unequal Outcomes in Academic Careers. Gender, Work \&
Organization, 2005. 12(1): p. 50-72.

[16] Heikkinen, S., A.-M. Lämsä, and M. Hiillos. Narratives by women managers about spousal support for their careers. Scandinavian Journal of Management, 2014. 30(1): p. 27-39.

[17] Woodward, D. Work $\square$ life balancing strategies used by women managers in British "modern" universities. Equal Opportunities International, 2007. 26(1): p. 6-17.

[18] Wilkes, L., D. Jackson, J. Daly, and W. Cross. The rise of the nurse academic leader: Pathways to Deanship. Nursing and Health, in press.

[19] Nelson, D.L.and R.J. Burke, Women executives: Health, stress, and success. The Academy of Management Executive, 2000. 14(2): p. 107-121.

[20] Lindquist, T.L., L.J. Beilin, and M.W. Knuiman. Influence of lifestyle, coping, and job stress on blood pressure in men and women. Hypertension, 1997. 29(1): p. 1-7.

[21] Ahmad, S.M., Z. Fakhr, and J. Ahmed. Working women work-life conflict. Business Strategy Series, 2011. 12(6): p. 289-302. 